\title{
Impacts of Divergent Moving Drives on Energy Efficiency and Performance of Various AMS in Operative Conditions
}

\author{
Martin Höhendinger ${ }^{1,2, * \mathbb{D}}$, Hans-Jürgen Krieg ${ }^{3}$, Reinhard Dietrich ${ }^{3}$, Stefan Rauscher ${ }^{3}$, Jörn Stumpenhausen ${ }^{2}$ \\ and Heinz Bernhardt ${ }^{1}$ (D) \\ 1 Chair of Agricultural Systems Engineering, TUM School of Life Sciences, Technical University of Munich, \\ Dürnast, 10, 85354 Freising, Germany; heinz.bernhardt@wzw.tum.de \\ 2 Department of Sustainable Agriculture and Energy Systems, University of Applied Sciences \\ Weihenstephan-Triesdorf, Am Staudengarten, 1, 85354 Freising, Germany; joern.stumpenhausen@hswt.de \\ 3 BEDM GmbH, Arthur-Piechler-Str., 1i, 86316 Friedberg, Germany; krieg@bedm.de (H.-J.K.); \\ dietrich@bedm.de (R.D.); rauscher@bedm.de (S.R.) \\ * Correspondence: martin.hoehendinger@tum.de; Tel.: +49-81-6171-6467
}

Citation: Höhendinger, M.; Krieg, H.-J.; Dietrich, R.; Rauscher, S.; Stumpenhausen, J.; Bernhardt, H. Impacts of Divergent Moving Drives on Energy Efficiency and Performance of Various AMS in Operative Conditions. Agriculture 2021, 11, 806. https://doi.org/ 10.3390/agriculture11090806

Received: 9 July 2021

Accepted: 19 August 2021

Published: 25 August 2021

Publisher's Note: MDPI stays neutral with regard to jurisdictional claims in published maps and institutional affiliations.

Copyright: (c) 2021 by the authors. Licensee MDPI, Basel, Switzerland. This article is an open access article distributed under the terms and conditions of the Creative Commons Attribution (CC BY) license (https:/ / creativecommons.org/licenses/by/ $4.0 /)$.

\begin{abstract}
In recent decades, the costs of energy in dairy farming increased mainly due to rising energy prices but also due to increased mechanisation and automatisation. Electric energy in dairy farming is essentially used for milking and milk cooling. However, the energy consumption of automatic milking systems (AMS) depend on many factors (e.g., machine generations, machine configurations and settings, and operative conditions). To evaluate the differences in performance and energy efficiency of AMS, the impact of different technologies within the attachment arm in practical conditions, a detailed quantification of energy consumption was carried out on two consecutive single box automatic milking systems (AMS) of a dairy farm in southern Bavaria (Germany). The AMS equipped with an electrical drive of the attachment arm was more efficient and showed a higher capacity regarding cows in the herd. The replacement of the pneumatic drive with electrical drives leads to higher energy consumptions of the milking robot but reduces the energy consumption of the air compressor. Hence, the energy efficiency of the electric attachment arm showed strong advantages in the energetic efficiency of the whole milking process. Advances of sustainability due to the increased performance are and should be investigated in further research.
\end{abstract}

Keywords: automatic milking system; energy efficiency; precision dairy farming; milking performance; robotic milking

\section{Introduction}

Energy consumption is one of the most important production factors in German dairy farming. Besides environmental impacts, the aspects of energy consumption in dairy farming are economic impacts due to increasing energy costs [1]. In recent decades the increase in energy costs in agriculture is mainly due to rising energy prices, but also due to increased mechanisation and automatisation on the farms [2]. In this context, especially the usage of automatic milking systems (AMS) in modern dairy farms is more and more popular worldwide [3]. Sales of automatic milking systems have risen in recent years [4]. A review by Shine et al. [1] found milking the largest consumer of electric energy, while the main consumption could not be assigned to a certain component. According to Pommer et al. [5], in dairy farming, 56\% to 70\% of the total energy consumption is used for milking and milk cooling. Milking requires a large amount of energy, with the vacuum pump as a component requiring a lot of energy [6]. A rising interest in energy efficiency and renewable energy technologies, improvements of energy independence and reduction of energy usage are the consequence [1]. According to this, Pommer [7] announces strong variations considerably depending on utilization and equipment. With an average of $0.42 \mathrm{kWh} /$ milking, the power consumption of the AMS is significantly higher than in 
conventional systems ( $0.28 \mathrm{kWh}$ on average) [7]. Bos [8] announced a $42 \%$ higher energy consumption compared to a conventional milking system. Hence, automatic milking increases electricity use on dairy farms [9]. Considering the operational costs of an AMS, electric consumption is one of the most relevant and uncontrollable balance items, ranging between $35 \%$ and $40 \%$ of the total annual operational costs [10].

AMS includes single-stall systems where robotic and milking functions are integrated as well as multi-stall systems with transportable robot devices combined with milking and detachment devices at each stall [11]. However, most AMSs are single-stall units where an isolated milking experience for the cow differs drastically from most conventional parlour systems [12]. According to De Koning [11], single-stall systems have a capacity of 55-60 cows, while multi-stall systems with 2 to 4 stalls are mentioned to milk 80 to 150 cows up to three times per day. This represents a maximal number of 180 milking events per day. AMS takes over the milking as well as all pre- and post-milking tasks of the milker [13]. Hence, the different labour conditions and computer-based herd management with monitoring of individual animals are probably the greatest modifications related to robotic milking [10]. Although robots have a theoretical milking time of $24 \mathrm{~h}$, the actual milking time is reduced by several hours depending on missed visits, system times, cleaning, etc. [4]. The AMS works continuously with a maximum milk yield of 100-120 L/h and station [14]. The milking capacity of an AMS is often expressed as the number of milkings per day, but additional criteria, such as herd size, milking frequency, or cow traffic, have an impact on the performance of an AMS [15]. However, Artmann [16] indicated in provisional analyses a clear decrease in the number of milkings when more than 45 highperformance cows are milked per AMS. Nevertheless, the variable number of cows and flow rate have the greatest influence on milk yield per AMS, and the milk yield could be maximized by milking the maximum number of cows per AMS with a value of between 2.40 and 2.60 milkings per cow and day [15].

The main differences in energy consumption were related to the air compressor and the vacuum pump compared to conventional milking [8]. For the energy demand of the milking system, the vacuum pump technology bears a great meaning in addition to the tuning of the milking system to the milk quantity [5]. Using frequency control showed a decreased energy consumption of the vacuum pump with $40 \%$ to $60 \%$ [8,17]. According to Calcante et al. [10] the energy used by AMS depends on many factors (e.g., machine generations, machine configurations and settings, and operative conditions). The impact of the technology of the attachment arm is not investigated in this context. Precise attachment requires a quick and accurate positioning of the teat cups [18]. Depending on configuration and manufacturer, the attachment arm is driven hydraulically, electrically and/or pneumatically [4]. Previous studies showed new AMS models have been launched, and previous models have been improved in recent years [10]. Detailed quantification of energy consumption is essential to achieve low operational costs [10].

Hence, the aim of the present study was to examine which components are the main energy consumers of the automatic milking system. The effects on the efficiency of the dairy system enterprise by a consecutive development step of milking robots with different drive systems (pneumatic, electric) shall be identified and quantified. To achieve this, milk production parameters, as well as the consumption of electric energy based on the two different system configurations, were evaluated.

The focus was on the measurement of the electric consumption of these AMS under practical conditions in the same operational circumstances as a practical farm. Subsequently, the impacts of the different configurations on the distribution of the electricity consumption of the components of the milking system were evaluated. To evaluate the efficiency of the different configurations, impacts on the production and herd management (e.g., herd size, herd performance and milking events and total milk production) were considered as comparative size. Advances in dairy efficiency were discussed focused on aspects of energetic efficiency and production performance of different milking systems. 


\section{Materials and Methods}

\subsection{Description of the Farm and the Investigated System Configurations}

For this research, the two consecutive single box automatic milking systems (AMS) of a dairy farm in southern Bavaria (Germany) are analysed in practical conditions during the winter months. Free cow traffic was adopted on the farm. The first configuration was the automatic milking system (AMS) Merlin 4 by Fullwood produced 2014. The energy consumption of the AMS (Merlin 4) was observed between December 2019 and March 2020. The second configuration was the $\mathrm{M}^{2}$ erlin by Fullwood produced 2020. The measurements for this configuration were carried out between December 2020 and March 2021.

The data regarding herd size and milk yield, as well as information about the use of capacity of the AMS during the observation periods, were collected from the AMS management software Crystal (Version 2.7, Fullwood, Vleuten, Netherlands) in both configurations. As standard preparation, each teat is cleaned and stimulated with two counter-rotating brushes, moving up and down 3 times each. The flow rate is calculated by the milking time recorded in the Crystal software and the total milk yield.

The components of the AMS considered in this research are directly connected to the milking process. These components are the milking robot, the vacuum pump, the air compressor and the heating unit, as well as the water reservoir for the boiling water cleaning system (BWAC). Both AMS were powered by Three-Phase $400 \mathrm{~V} / 50 \mathrm{~Hz}$ (Table 1). The energy consumption of the AMS milking unit includes the milk pump, electric and electronic devices (e.g., printed circuit board, touch screen). In the $\mathrm{M}^{2}$ erlin configuration, the electric drives of the attachment arm are included in the energy consumption of the milking robot.

Table 1. Technical and energetic characteristics of the considered energy consumers of the different AMS configurations.

\begin{tabular}{ccc}
\hline Production System & Configuration Merlin 4 & Configuration $\mathbf{M}^{2}$ erlin \\
\hline \multirow{3}{*}{ Automatic milking system } & System control $0.5 \mathrm{~kW}$ & System control: $0.5 \mathrm{~kW}$ \\
& Milk pump: $1.5 \mathrm{~kW}$ & Milk pump: $1.5 \mathrm{~kW}$ \\
& Pneumatic drives & Electric drives \\
\hline Vacuum pump & \multicolumn{2}{c}{ dry claw vacuum pump: $3.0 \mathrm{~kW}$} \\
\hline \multirow{2}{*}{ Air compressor } & scroll compressor: $3.0 \mathrm{~kW}$ & piston compressor: $3.0 \mathrm{~kW}$ \\
& 250 L pressure vessel & 90 L pressure vessel \\
\hline Hot water boiler & CitrinSolar GmbH Type ESH6DN40: $4,5 \mathrm{~kW} 230 / 400 \mathrm{~V}$ \\
\hline
\end{tabular}

The vacuum for milking is provided by a frequency-controlled dry claw vacuum pump with a maximum pressure of $400 \mathrm{hPa}$ powered by a $3.0 \mathrm{~kW}$ motor for the Merlin 4 and $\mathrm{M}^{2}$ erlin AMS, respectively.

Compressed air is used for opening/closing the entrance and exit gates of the milking stall and for moving the robotic arm toward the udder in the Merlin 4 system. In this configuration, compressed air is supplied by a $3.0 \mathrm{~kW}$ scroll compressor (RSDK-C 3.0, RENNER GmbH Kompressoren, Güglingen, Germany) combined with a 250 L pressure vessel. In the $\mathrm{M}^{2}$ erlin milking system, compressed air is only used for opening/closing the entrance, which is provided by a $3.0 \mathrm{~kW}$ piston compressor (REKO 500/90, RENNER $\mathrm{GmbH}$ Kompressoren, Güglingen, Germany) combined with a 90 L pressure vessel. The minimum pressure is 8 bar, and the maximum pressure is 10 bar. After every milking, the milk unit is cleaned with water at room temperature. Subsequently, water and milk are removed with compressed air.

Both AMS models are equipped with a boiling water cleaning system (BWAC), which cleans the milking system three times every day. The $240 \mathrm{~L}$ hot water boiler has a $4.5 \mathrm{~kW}$ heating unit. The used water is warmed up to $92{ }^{\circ} \mathrm{C}$ from a starting temperature of $45^{\circ} \mathrm{C}$.

Concentrate feed supply screws are not considered as it is assumed this system component is independent of the efficiency of the milking process and depends on each 
farm's individual circumstances. The energy consumption of the milk cooling system is independent of milk harvesting and depends mainly on the daily milk yield. Hence it is not considered in the observation.

\subsection{Technical Equipment for the Measurements}

The energy consumption of the different system components is measured as in [19] continuously by digital smart meters (certified 3-phase meters for measurement of active power up to $460 \mathrm{~V} / 65 \mathrm{~A}$ with 3 digital inputs and RS-485 interface, accuracy 1\%). According to the authors, the smart meters are directly connected via serial bus technology using Modbus RTU protocol to an intelligent gateway (Ewon flexy). The gateway collects and selects the received data and sends it via standard internet technology transmission control protocol (TCP) to a central database server using InfluxDB (Influxdata Inc., San Francisco, CA, USA) as database management software [19]. The monitoring and analytics of the data are done by the tool Grafana [19]. The Grafana dashboard allows detailed time series analysis of single or grouped values, e.g., active power, apparent power, frequency, cos phi, voltages and currents [19]. Active energy is analysed as the machinery does not use inductive fields, and the energy provider accounts for the active energy consumption of the farm. The effects of apparent energy and reactive energy are not considered for this research. The active energy consumption is recorded continuously in $5 \mathrm{~s}$ intervals. For the analysis, the continuously recorded active energy consumption of the relevant AMS components are aggregated to hourly sums and exported from the InfluxDB by Grafana into a CSV data set.

\subsection{Statistical Analysis}

The statistical analysis was performed with MATLAB version R2020a (The MathWorks, Inc., Natick, MA, USA). The active energy consumption of every component was summarized for everyday by date. Measurements of the different components with the same date were matched according to the day of the year. Days with an incomplete recording or missing data from one or more components were extracted and removed from the data.

The production data were merged to the consumption according to the date. Subsequently, the daily consumption of active energy in total, the daily consumption per cow milked, the consumption per milking OK (successful milking event), as well as the total milking events and the consumption per litre of milk were calculated.

The data of the active energy consumption as well as the production parameters cows in the system, milking events, milking events $\mathrm{OK}$, milk yield and operational time were characterized by a one-way analysis of variance.

The efficiency of every component and the total system, the active energy consumption was investigated relative to the production parameters, e.g., milk yield per day, milking events and number of cows in the system. To elaborate on significant differences in thMEMe active energy consumption between the two configurations, a one-way analysis of variance analysis was carried out as well. The independent group parameter was the AMS configuration for both analyses. Differences were assumed to be significant at a $p<0.05$.

\section{Results}

\subsection{Milk Production and Process Evaluation}

During the two observation periods of 3 month each, the average herd size was 55.8 cows in the first and 66.6 cows in the second configuration (Table 2).

Due to more cows and an increased number of milking events as a consequence, the overall milk production was $1872.2 \mathrm{~kg}$ in the second observation period and in total $294.3 \mathrm{~kg}$ higher compared to the first observation period, with $1577.9 \mathrm{~kg}$ mean milk production per day. The production data related to the AMS were all significantly higher in the $\mathrm{M}^{2}$ erlin system $(p<0.001)$. The mean milk yield per cow per day was similar between both observation periods (28.25 kg/day and cow (Merlin 4); $28.11 \mathrm{~kg} /$ day and cow ( $\left.\mathrm{M}^{2} \mathrm{erlin}\right)$ ) and did not differ significantly $(p=0.3408)$. According to the increased milking frequency, 
the mean milk yield per milking decreased significantly. Additionally, the mean flow rate increased with the $\mathrm{M}^{2}$ erlin system.

Table 2. Differences in the milk production in dependency of the AMS.

\begin{tabular}{|c|c|c|c|c|c|c|c|}
\hline & Unit & Merlin 4 & SEM & $\mathbf{M}^{2}$ erlin & SEM & F-Value & $p$-Value \\
\hline Herd size & $(n)$ & 55.8 & 0.3079 & 66.6 & 0.3079 & 610.7502 & $<0.001$ \\
\hline Mean milking events & (n/day) & 134.6 & 0.6831 & 162.3 & 0.6831 & 824.1022 & $<0.001$ \\
\hline Mean successful milking events & (n/day) & 119.9 & 1.0624 & 151.4 & 1.0624 & 438.9369 & $<0.001$ \\
\hline Relative failed milking events & $(\%)$ & 0.72 & 0.001 & 0.24 & 0.001 & 12.4743 & $<0.001$ \\
\hline Mean milking frequency & $(n /$ cow $)$ & 2.15 & 0.0159 & 2.27 & 0.0159 & 30.7972 & $<0.001$ \\
\hline Mean flow rate & $(\mathrm{kg} / \mathrm{min})$ & 1.38 & 0.0064 & 1.67 & 0.0064 & 1037.9 & $<0.001$ \\
\hline Mean milk yield & (kg/day) & 1577.9 & 0.0069 & 1872.2 & 0.0069 & 918.4604 & $<0.001$ \\
\hline Mean milk yield & (kg/day and cow) & 28.25 & 0.1070 & 28.11 & 0.1070 & 0.9139 & 0.3408 \\
\hline Mean milk per milking & (kg/cow and milking) & 13.17 & 0.0801 & 12.41 & 0.0801 & 45.5497 & $<0.001$ \\
\hline
\end{tabular}

\subsection{Analysis of the Energy Consumption}

The energy consumption of the two AMS configurations is different regarding the single system components and consequently the whole system. Therefore, the total active energy consumption of the whole system is presented first and subsequently the energy consumptions of the single system components.

\subsubsection{Daily Active Energy Consumption of the AMS Related to System Components}

The total active energy consumption of the AMS decreases significantly $(p<0.001)$ with the evolution step from $38.3356 \mathrm{kWh}$ in the Merlin 4 to $35.8308 \mathrm{kWh}$ in the $\mathrm{M}^{2}$ erlin system (Table 3). This development results from significant $(p<0.001)$ lower active energy consumption of the vacuum pump and the air compressor. Conversely, the milking robot $\mathrm{M}^{2}$ erlin demands a higher active energy consumption compared to the Merlin 4 . The energy consumption of the boiling water cleaning system (BWAC) did not differ between the two AMS configurations $(p=0.8198)$.

Table 3. A comparison of the daily active energy consumption of the Merlin 4 and $\mathrm{M}^{2}$ erlin AMS configuration.

\begin{tabular}{clcccccc}
\hline Reference Parameter & Unit & Merlin 4 & SEM & M $^{2}$ erlin & SEM & F-Value & $p$-Value \\
\hline Total active energy consumption per day & $\mathrm{kWh} /$ day & 38.3356 & 0.1917 & 35.8308 & 0.1826 & 89.4905 & $<0.001$ \\
Energy consumption milking robot & $\mathrm{kWh} /$ day & 2.3305 & 0.0214 & 5.5308 & 0.0203 & 11769 & $<0.001$ \\
Energy consumption vacuum pump & $\mathrm{kWh/day}$ & 9.1712 & 0.1500 & 7.4308 & 0.1430 & 70.5238 & $<0.001$ \\
Energy consumption air compressor & $\mathrm{kWh} /$ day & 10.7542 & 0.0432 & 6.7508 & 0.0412 & 4503.4 & $<0.001$ \\
Energy consumption BWAC & $\mathrm{kWh/day}$ & 16.0797 & 0.1231 & 16.1185 & 0.1173 & 0.0521 & 0.8198 \\
\hline
\end{tabular}

\subsubsection{Active Energy Consumption of the AMS Related to System Performance}

As a consequence, the decrease in the energy consumption is observed relative to the energy consumption per cow, relative to the milking events in total and milkings OK as well as the energy consumption per $\mathrm{kg}$ milk yield (Table 4). All mentioned observations are significant with $p<0.0001$. In particular, in the relative comparison, the high F-values indicate a strong dependency of the energy consumption from the AMS configuration.

\subsubsection{Active Energy Consumption of the AMS Related to Milk Yield}

The observation of the different system components indicated the reasons for the decreasing energy consumption between the two system configurations (Table 5). The applications of pneumatic driving elements were reduced in the $\mathrm{M}^{2}$ erlin. Hence, energy consumption for compressed air production decreases by nearly $48 \%$. On the other hand, the electric energy consumption of the milking robot $\mathrm{M}^{2}$ erlin for electric driving elements increased. Therefore, the active energy demand of the $\mathrm{M}^{2}$ erlin milking robot was $0.0030 \mathrm{kWh} / \mathrm{kg}$ milk, twice the energy consumption compared to the Merlin 4 milking 
robot $(p<0.001)$. The energy consumption per kg milk for vacuum supply and the BWAC was lower in the $\mathrm{M}^{2}$ erlin configuration $(p<0.001)$.

Table 4. A comparison of the active energy consumption of the Merlin 4 and $\mathrm{M}^{2}$ erlin AMS configuration related to selected production parameters.

\begin{tabular}{|c|c|c|c|c|c|c|c|}
\hline Reference Parameter & Unit & Merlin 4 & SEM & $\mathbf{M}^{2}$ erlin & SEM & F-Value & $p$-Value \\
\hline Active energy consumption per cow & kWh/day/cow & 0.6861 & 0.0045 & 0.5396 & 0.0043 & 546.9405 & $<0.001$ \\
\hline $\begin{array}{c}\text { Active energy consumption per milking } \\
\text { events total }\end{array}$ & $\mathrm{kW}$ & 0.2856 & 0.0017 & 0.2215 & 0.0016 & 718.5019 & $<0.001$ \\
\hline $\begin{array}{c}\text { Active energy consumption per milking } \\
\text { events OK }\end{array}$ & $\mathrm{kWh} / \mathrm{n}$ & 0.3202 & 0.0024 & 0.2385 & 0.0023 & 590.0929 & $<0.001$ \\
\hline Active energy consumption & $\mathrm{kWh} / \mathrm{kg}$ milk & 0.0243 & 0.0001 & 0.0192 & 0.0001 & 662.7110 & $<0.001$ \\
\hline
\end{tabular}

Table 5. Daily energy consumption of the different energy consumers and the total AMS systems related to the milk yield.

\begin{tabular}{cccccccc}
\hline System Configuration & Unit & Merlin 4 & SEM & M $^{2}$ erlin & SEM & F-Value & $p$-Value \\
\hline Milking robot & Wh/kg milk & 1.5 & 0.0000 & 3.0 & 0.0000 & 4503.4 & $<0.001$ \\
Vacuum pump & Wh/kg milk & 5.8 & 0.0001 & 4.0 & 0.0001 & 187.9703 & $<0.001$ \\
Air compressor & Wh/kg milk & 6.8 & 0.0000 & 3.6 & 0.0000 & 5907.0 & $<0.001$ \\
BWAC & Wh/kg milk & 10.2 & 0.0001 & 8.6 & 0.0001 & 204.6392 & $<0.001$ \\
Total & Wh/kg milk & 24.3 & 0.0001 & 19.2 & 0.0001 & 662.7110 & $<0.001$ \\
\hline
\end{tabular}

\section{Discussion}

\subsection{Observation Period and Data Selection}

The two observation periods differed by one year. These were chosen as behavioural changes in the herd dynamic in combination with the increasing number of cows in the barn system were likely. To avoid the impacts of these herd dynamic processes on the efficiency of the milking system, this period was assumed to be appropriate. Additionally, natural impacts like temperature or day length were assumed to have an impact on behaviour or technical systems, such as fresh water temperature. The presence of seasonal trends Shortall et al. [20] found was not analysed in this research. By selection of identical periods of the season, these impacts were assumed to be equal for both observation periods. Bias due to seasonal issues was assumed to be negligible by data recordings in the same period of two consecutive years. However, those findings have the potential to assist in developing future strategies that may improve the competitiveness of AMS [20].

\subsection{Differences in the Milking Performance}

The comparison of the production data of both AMS configurations shows an increased performance of the $\mathrm{M}^{2}$ erlin compared to the Merlin 4 . The milk yield per cow was not significantly affected by the change of the AMS. Therefore, a homogeneous herd and feed management can be assumed, and the effects of changed feeding strategies can be neglected. The milk yield per cow does not differ between the two system configurations. This indicates the higher total milk production as a consequence of more cows being milked, which generated an average of 27.7 more milking events per day in the $\mathrm{M}^{2}$ erlin in combination with more cows in the system. Additionally, the mean milk yield per milking decreased in the $\mathrm{M}^{2}$ erlin. The difference is likely to result from an increased milking frequency with the $\mathrm{M}^{2}$ erlin, while the milk production per cow and day did not. According to this, the time efficiency of the $\mathrm{M}^{2}$ erlin system and, consequently, the performance of the system is higher compared to the Merlin 4 system.

Other reasons are a lower error ratio in combination with increased milking frequency. Additionally, the mean flow rate was increased in the $\mathrm{M}^{2}$ erlin system, which indicates a better stimulation of the udder. The increase in the total milk yield per day results from more cows that are in the system and milked. This subsequently supports the decrease in energy consumption per kg milk. 
Overall, the milking events per day in the examined AMS were less (134.6 (Merlin4); 161.3 ( $\mathrm{M}^{2}$ erlin)) compared to 189 (A4) Calcante et al. [10] observed. Under the assumption of maximal three milkings per cow, the maximal capacity of the AMS did not increase since De Koning 2004 [11]. However, the observed milking events in this research are matching with the data for heavy milking cows of the DLG e.V [21] official test. Hence, it is likely that this difference is caused by the flow rate of the individual breed of the herd at the research farm. Additionally, according to Castro et al. [15], the variable number of cows and flow rate had the greatest influence on milk yield per AMS. Other impacts on the performance of the milking system like cleaning or service appointments DLG e.V. [22] were not considered. The cleaning system was the same in both observation periods, and service appointments were not recorded.

\subsection{Improvement of Electric Efficiency for Different Reasons}

The difference in energy consumption of the $\mathrm{M}^{2}$ erlin system in total $\mathrm{kWh}$ per day as well as the energy consumption per kg of milk compared to the Merlin 4 system may be the result of the combination of different effects on the AMS components.

\subsubsection{Shift between Pneumatic and Electric Drives}

The milking robot $\mathrm{M}^{2}$ erlin consumes more energy compared to the Merlin 4. This is the consequence of the transformation from pneumatic drives to electric drives. According to this, the lower demand of compressed air, for less pneumatic drives, caused a decreased energy consumption of the air compressor. Additionally, Calcante et al. [10] observed this shift in energy consumption between system components. They assumed the replacement of the former air-operated arm for horizontal movements with an electric drive as the reason [10]. Shortall et al. [20] described an electric energy consumption of $16.5 \mathrm{Wh} / \mathrm{L}$ milk (range $=13-23 \mathrm{Wh} / \mathrm{L}$ milk). In both Merlin AMS systems, the demand for electric energy for compressed air was lower with $6.8 \mathrm{Mh} / \mathrm{L}$ milk (Merlin 4) and 3.6 Wh $/ \mathrm{kg}$ milk ( $\mathrm{M}^{2} \mathrm{erlin}$ ). Differences in the energy efficiency of the scroll compressor in the Merlin 4 system compared to the energy efficiency of the piston compressor in the $\mathrm{M}^{2}$ erlin system were not considered. However, piston compressors are more appropriate for lower utilisation rates. Hence, the piston compressor is more suitable for the reduced amount and unsteady requirement of compressed air in the $\mathrm{M}^{2}$ erlin system. Since electric drives have advantages in adjustability and energy transmission compared to pneumatic or hydraulic drives [23], the gain in energy efficiency is assumed to result due to the different attachment arm systems.

\subsubsection{Energy Efficiency of the Milking and Cleaning Process}

The energy consumption for vacuum supply is lower in the $\mathrm{M}^{2}$ erlin system. This might result from the renewed vacuum pump. However, the renewed vacuum pump has the same technical settings and configurations as the vacuum pump of the Merlin 4 system. As more cows were milked and more milking events took place in the second observation period, a slightly increased energy consumption would be expected. One possible explanation is a lower leakage of vacuum because of a faster or more precise attachment of the teat cups to the udder. This might cause the decreased energy consumption.

The BWAC is not affected by the different system configurations. Since three main cleaning events were required, there was no difference found between the energy consumption in the two-system configuration (Table 3). The cleaning system is not affected by the amount of milk or the efficiency of milk production. Hence, the energy consumption is determined by the frequency of the main cleaning cycles that are regulated by legal requirements.

The energy consumption caused by the main cleaning process of the milking robot, the vacuum pump as well as the compressor were not recorded separately. In further research, this should be considered additionally to the energy consumption of the BWAC. However, this energy consumption is included in the data for the total energy consumption of the AMS. Hence, the effect for the evaluation of the overall efficiency is negligible. 
For the energy consumption of the milking process, Shortall et al. [20] announces 20.7 Wh/L milk (range $=14-26 \mathrm{Wh} / \mathrm{L}$ milk) for the processes of milk pumping, vacuum pumping, water heating within the AMS and miscellaneous electrical devices associated with the AMS. Compared to the current data, the mean energy consumption focused on these components arises to 17.5 Wh/L milk (Merlin 4) and 15.6 Wh/L milk (M²erlin). Both mean values are lower but in the range of the study by Shortall et al. [20].

\subsection{Similar Energy Consumption Compared to other Milking Systems}

In conventional milking systems, Upton et al. [24] found a mean electrical energy consumption of $8.44 \mathrm{Wh} / \mathrm{L}$ of milk harvested with milking machines consisting of vacuum pumps and milk pumps [24]. However, Hörndal [6] also detected lower energy demand for a milking robot compared to the conventional milking parlour. According to the data of Hörndal [6], the energy consumption was $26.3 \mathrm{Wh} / \mathrm{L}$ of milk, excluding energy for cooling. The mean electrical energy consumption in the Merlin 4 system with $24.3 \mathrm{Wh} / \mathrm{kg}$ milk, respectively, $19.2 \mathrm{Wh} / \mathrm{kg}$ milk in the $\mathrm{M}^{2}$ erlin system were both higher compared to the conventional milking system. However, Upton et al. [24] only considered the vacuum pump and the milk pump for their research. Focused on these two components, the energy consumption of both AMS systems is lower compared to the conventional milking systems.

In similar research, Calcante et al. [10] realized a total energy consumption per day with $60.32 \mathrm{kWh} / \mathrm{d}$ for an A3 Next (Lely) and $45.43 \mathrm{kWh} / \mathrm{d}$ for an A4 AMS (Lely), which is higher compared to the Merlin 4 with $38.34 \mathrm{kWh} / \mathrm{d}$ and $\mathrm{M}^{2}$ erlin with $35.83 \mathrm{kWh} / \mathrm{d}$ in the current research. The differences may result from the steam cleaning system of the A3 Next and the A4 and from a different number of milking events. However, in the current research, the heating for the BWAC was also considered, which was not part of the milking unit in Calcante et al. [10]. Hence, the electrical energy consumption of $20.7 \mathrm{Wh} / \mathrm{L}$ milk for an A3 Next AMS (Lely) and 24.4 Wh/L of milk for an A4 AMS (Lely) can be assumed to be slightly higher compared to the energy consumption shown by the Merlin 4 and the $\mathrm{M}^{2}$ erlin AMS. On the other hand, in the current study, the cleaning process was not analysed separately. Hence, the energy consumption for milking can only be assumed to be lower in the current study. Additionally, the energy consumption measured in this research was compared to an official testing by the DLG e.V. [21]. The electrical energy consumption of the Merlin 4 in the current research was similar to the total energy consumption of the Merlin 4 AMS mentioned in the results of the official testing report of DLG e.V. [21]. Variations can be determined from differences in the installed system, e.g., the length of the milk line [21], which is likely in the practical conditions of this study. Compared to the AMS Monobox by GEA Farm Technologies GmbH, Düsseldorf, Deutschland, which was tested by the DLG e.V. [25], the energy consumption among practical conditions were lower for both Fullwood AMS. Regarding the official test, the Monobox consumes $26.83 \mathrm{Wh} / \mathrm{kg}$ milk [25], which is also higher than the analysis of Calcante et al. [10].

According to the official test results, the analysis and methodology can be assumed to be suitable to examine the energy consumption of the two AMSs in practical conditions. In consequence, the measured data can be assumed to be transferrable to other dairy farms. Nevertheless, the comparison between different studies regarding different AMS is difficult. In particular, the methods for the measurement should be equal for all studies. The official measurements of DLG e.V. [21] and DLG e.V. [25] show the importance of this neutral comparison and give an example for a suitable test routine. To enable better comparability and to ensure broad awareness of energy efficiency, this test should be mandatory for all AMSs.

\section{Conclusions}

The electrical drive of the attachment arm was more efficient than the pneumatic one. This was achieved due to lower energy consumption in combination with a higher milking and production performance. The replacement of the pneumatic drive with electrical drives leads to higher energy consumptions of the milking robot but reduces the 
energy consumption of the air compressor. Considering the increased performance of more milking events and reduce the energy consumption of the total AMS, the energy efficiency of the electric attachment arm showed strong advantages in the energetic efficiency of the whole milking process. Impacts of herd size can be neglected due to the overall reduced energy consumption on the configuration with the electric drives.

However, it is shown that equal measurement and testing routines are essential for comparisons of energy efficiency. Hence, international standards for these tests are required. Aspects of more efficient herd management, an increased return of investment and improvements of sustainability due to the increased performance are likely. These effects should be investigated in further research.

Author Contributions: Conceptualization, M.H., J.S. and H.B.; methodology, M.H., H.-J.K., S.R. and R.D.; software, S.R. and R.D.; validation, M.H., S.R.; formal analysis, M.H.; investigation, M.H.; resources, M.H.; data curation, S.R.; writing—original draft preparation M.H.; writing-review and editing, M.H.; visualization, M.H.; supervision, J.S. and H.B.; project administration, H.B.; funding acquisition, J.S. and H.B. All authors have read and agreed to the published version of the manuscript.

Funding: The project was supported by funds of the Federal Ministry of Food and Agriculture (BMEL) based on a decision of the Parliament of the Federal Republic of Germany via the Federal Office for Agriculture and Food (BLE) under the innovation support programme.

Data Availability Statement: The data presented in this study are available on request from the corresponding authors.

Acknowledgments: The authors are grateful to the farmer Micheal Posch and his family who facilitated access to the farms data and the personal support of the research.

Conflicts of Interest: Author M.H. was employed by Lemmer-Fullwood after the generation and analyses of the presented data. Lemmer-Fullwood had no role in the design of the study; in the collection, analyses or interpretation of data; in the writing of the manuscript; or in the decision to publish the results. The funders (BMEL/BLE) had no role in the design of the study; in the collection, analyses or interpretation of data; in the writing of the manuscript; or in the decision to publish the results.

\section{References}

1. Shine, P.; Upton, J.; Sefeedpari, P.; Murphy, M.D. Energy Consumption on Dairy Farms: A Review of Monitoring, Prediction Modelling, and Analyses. Energies 2020, 5, 1288. [CrossRef]

2. Rajaniemi, M.; Jokiniemi, T.; Alakukku, L.; Ahokas, J. Electric energy consumption of milking process on some Finnish dairy farms. Agric. Food Sci. 2017, 26, 160-172. [CrossRef]

3. De Koning, K. Automatic milking — common practice on dairy farms. In The First North American Conference on Precision Dairy Management; DeLaval International AB: Tumba, Sweden, 2010.

4. KTBL Editor (Ed.) Automatische Melksysteme. In Verfahren-Kosten-Bewertung. Kuratorium für Technik und Bauwesen in der Landwirtschaft; KTBL: Darmstadt, Germany, 2013.

5. $\quad$ Pommer, R.; Eckel, H.; Hartmann, W.; Kämper, H. Energiebedarf in der Milchviehhaltung. In KTBL-Heft. Kuratorium für Technik und Bauwesen in der Landwirtschaft; KTBL: Darmstadt, Germany, 2014.

6. Hörndahl, T. Energy Use in Farm Buildings. In A Study of 16 Farms with Different Enterprises Revised and Translated, 2nd ed.; Swedish University of Agricultural Sciences: Uppsala, Sweden, 2008.

7. Pommer, R.; Pache, S.; Heber, I.; Rindfleisch, A. Automatische Melksysteme in Sachsen. Available online: https:/ / publikationen. sachsen.de/bdb/artikel/18690/documents/25137 (accessed on 9 February 2020).

8. Bos, K. Energy consumption on frams with an AM-system. In Automatic Milking, A Better Understanding; Meijering, A., Hogeveen, H., de Koning, C.J.A.M., Eds.; Wageningen Academic Publishers: Wageningen, The Netherlands, $2004 ;$ pp. 75-76.

9. Rotz, C.A.; Coiner, C.U.; Soder, K.J. Automatic Milking Systems, Farm Size, and Milk Production. J. Dairy Sci. 2003, $12,4167-4177$. [CrossRef]

10. Calcante, A.; Tangorra, F.M.; Oberti, R. Analysis of electric energy consumption of automatic milking systems in different configurations and operative conditions. J. Dairy Sci. 2016, 5, 4043-4047. [CrossRef] [PubMed]

11. De Koning, K.; Rodenburg, J. Automatic milking: State of the art in Europe and north America. In Automatic Milking, A Better Understanding; Meijering, A., Hogeveen, H., de Koning, C.J.A.M., Eds.; Wageningen Academic Publishers: Wageningen, Germany, 2004.

12. Jacobs, J.A.; Siegford, J.M. Invited review: The impact of automatic milking systems on dairy cow management, behavior, health, and welfare. J. Dairy Sci. 2012, 5, 2227-2247. [CrossRef] [PubMed] 
13. Jungbluth, T.; Büscher, W.; Krause, M. Technik Tierhaltung. UTB; Verlag Eugen Ulmer: Stuttgart, Germany, 2017.

14. Stoffers, I. Anforderungen des automatischen Melkens an die Milchkühung und deren technische Lösungen. In Lebensmittel aus dem Stall. Tagung Tier-Technik 2006, Tagung Hannover, 13. November 2006; VDI-Verlag: Düsseldorf, Germany, 2006 ; pp. 15-27.

15. Castro, A.; Pereira, J.M.; Amiama, C.; Bueno, J. Estimating efficiency in automatic milking systems. J. Dairy Sci. 2012, 2, 929-936. [CrossRef] [PubMed]

16. Artmann, R. System capacity of single box AMS and effect on the milk performance. In Automatic Milking, A Better Understanding; Meijering, A., Hogeveen, H., de Koning, C.J.A.M., Eds.; Wageningen Academic Publishers: Wageningen, Germany, 2004; pp. 474-475.

17. Neser, S.; Nieber, J.; Bonkoss, K. Stromverbrauch und Energieeffizienz im landwirtschaftlichen. In Energiewende und Landwirtschaft. Landtechnische Jahrestagung am 22. November 2012 im Bildungszentrum Kloster Banz, Bad Staffelstein; Bayerische Landesanstalt für Landwirtschaft (LfL), ES-Druck: Freising-Tüntenhausen, Germany, 2012; pp. 23-35.

18. Artmann, R. Technik der automatischen Melksysteme. In Automatische Melksysteme. Stand der Technik, Melkphysiologie und Milchhygiene, Tierhaltung, bauliche Lösungen, Praxiserfahrungen, Management und Wirtschaftlichkeit; Schön, H., Ed.; Landwirtschaftsverlag: Münster-Hiltrup, Germany, 2000; pp. 18-27.

19. Höhendinger, M.; Höld, M.; Hijazi, O.; Treiber, M.; Bauerdick, J.; Frech, L.; Dietrich, R.; Krieg, H.J.; Stumpenhausen, J.; Bernhardt, H. Cowenergy-possibilities of energy management in energy self-sufficient dairy cowsheds. In Bio-Economy and Agri-Production. Concepts and Evidence; Bochtis, D., Ed.; Academic Press: San Diego, CA, USA, 2021; pp. 159-172.

20. Shortall, J.; O'Brien, B.; Sleator, R.; Upton, J. Daily and seasonal trends of electricity and water use on pasture-based automatic milking dairy farms. J. Dairy Sci. 2018, 2, 1565-1578. [CrossRef] [PubMed]

21. DLG. DLG-Prüfbericht 6235F Lemmer-Fullwood GmbH Fullwood Merlin. In Hygiene, Verbrauchskennwerte; DLG: Frankfurt, Germany, 2014.

22. DLG. 100 Antworten zu automatischen Melksystemen. In Praxisempfehlungen zu Anforderungen an Mensch und Tier, Management, Haltung, Fütterung, Gesundheit; DLG-Verlag: Frankfurt, Germany, 2010.

23. Bartenschlager, J.; Hebel, H.; Schmidt, G. Handhabungstechnik mit Robotertechnik. In Funktion, Arbeitsweise, Programmierung. Viewegs Fachbücher der Technik; Vieweg+Teubner Verlag: Wiesbaden, Germany, 1998.

24. Upton, J.; Humphreys, J.; Koerkamp, P.G.; French, P.; Dillon, P.; de Boer, I. Energy demand on dairy farms in Ireland. J. Dairy Sci. 2013, 10, 6489-6498. [CrossRef] [PubMed]

25. DLG. DLG-Prüfbericht 6928 GEA Farm Technologies GmbH Automatisches Melksystem Monobox. In Verbrauchskennwerte Melken, Reinigen Leerlauf, Groß-Umstadt; DLG: Frankfurt, Germany, 2018. 